\title{
Which Score Should Be Used for Risk Stratification of Ischemic Stroke in Patients With Atrial Fibrillation
}

\author{
- A Simple or Detailed Approach? -
}

Takanori Ikeda, MD, PhD

A trial fibrillation (AF) is a common cardiac arrhythmia, the incidence of which increases with age. Approximately $1.5 \%$ of the general population in Japan has at least 1 type of AF.1,2 AF is known to be associated with an increased risk of ischemic stroke and all-cause mortality. When patients develop ischemic stroke (cerebral infarction) because of $\mathrm{AF}$, it is generally attributed to left atrial thromboembolism. The risk of ischemic stroke in patients with AF depends on associated stroke risk factors. The management of patients with AF involves 4 objectives: (1) prevention of thromboembolism, (2) rhythm control, (3) rate control, and (4) upstream therapy. Of these, prevention of thromboembolism (antithrombotic therapy) is the most important for managing AF. The ACCF/AHA guidelines in the USA, ${ }^{3}$ the CCS guidelines in Canada, ${ }^{4}$ and the JCS guidelines in $\mathrm{Japan}^{5}$ recommend using the conventional stroke risk stratification scheme, the $\mathrm{CHADS}_{2}$ (congestive heart failure, hypertension, age $>75$ years, diabetes mellitus, and stroke [double]) score, for antithrombotic therapy in patients with nonvalvular AF. ${ }^{6}$ On the other hand, guidelines in Europe ${ }^{7}$ recommend the use of a more complicated scheme, namely, the $\mathrm{CHA}_{2} \mathrm{DS}_{2}-\mathrm{VASc}$ (congestive heart failure, hypertension, age $>75$ years [double], diabetes mellitus, stroke [double], vascular disease, age: 65-75 years, and sex category) score for an increased risk of ischemic stroke with HAS-BLED (hypertension,

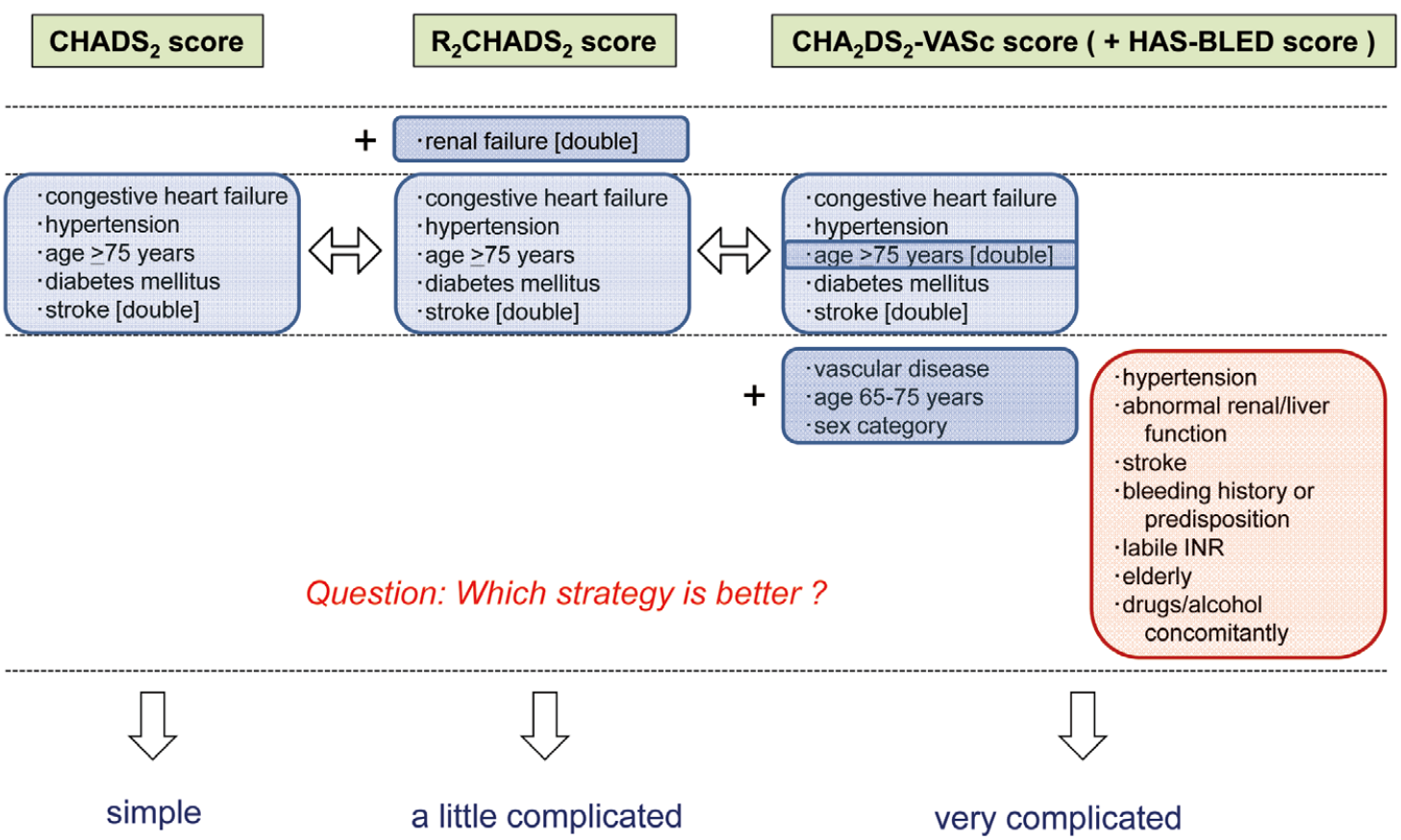

Figure. Comparison of 3 proposed scores for stratifying patients with non-valvular atrial fibrillation at risk for thromboembolism.

The opinions expressed in this article are not necessarily those of the editors or of the Japanese Circulation Society.

Received April 4, 2014; accepted April 4, 2014; released online May 7, 2014

Department of Cardiovascular Medicine, Toho University Faculty of Medicine, Tokyo, Japan

Mailing address: Takanori Ikeda, MD, PhD, Department of Cardiovascular Medicine, Toho University Faculty of Medicine, 6-11-1

Omorinishi, Ota-ku, Tokyo 143-8541, Japan. E-mail: ikety5@gmail.com

ISSN-1346-9843 doi:10.1253/circj.CJ-14-0409

All rights are reserved to the Japanese Circulation Society. For permissions, please e-mail: cj@j-circ.or.jp 
abnormal renal/liver function, stroke, bleeding history or predisposition, labile INR, elderly $>65$ years, and drugs/alcohol concomitantly) in order to avoid major bleeding complications. Recently, an alternative $\mathrm{R}_{2} \mathrm{CHADS}_{2}$ (renal failure [double], congestive heart failure, hypertension, age $>75$ years, diabetes mellitus, and stroke [double]) score was proposed to improve the precision of risk stratification by incorporating renal failure into the CHADS 2 score. ${ }^{8}$ These novel scores may outperform the $\mathrm{CHADS}_{2}$ scoring system in estimating the risk of ischemic stroke in AF patients.

\section{Article p1481}

In this issue of the Journal, Hoshino et $\mathrm{al}^{9}$ assess the predictive value of the $\mathrm{CHADS}_{2}, \mathrm{CHA}_{2} \mathrm{DS}_{2}-\mathrm{VASc}$, and $\mathrm{R}_{2} \mathrm{CHADS}_{2}$ scores for poor outcome in stroke patients with a prior history of coronary artery disease. Multivariate analysis showed that $\mathrm{CHADS}_{2}>2$ (odds ratio $=1.65$ ), $\mathrm{CHA}_{2} \mathrm{DS}_{2}-\mathrm{VASc}>4$ (odds ratio $=1.60$ ), and $\mathrm{R}_{2} \mathrm{CHADS}_{2}>3$ (odds ratio $=1.57$ ) significantly predicted a poor outcome. Therefore, all 3 can be used as prognostic models in a high-risk patient population. Furthermore, the authors compared the predictive value for poor outcome among the 3 scores and found they were not significantly different. The $\mathrm{CHADS}_{2}$ score does not include many common stroke risk factors, whereas the $\mathrm{CHA}_{2} \mathrm{DS}_{2}-\mathrm{VASc}$ and $\mathrm{R}_{2} \mathrm{CHADS}_{2}$ scores include some (Figure). Herein lies the question: Which score allows better risk stratification for ischemic stroke in high-risk patients with $\mathrm{AF}$ ? Of the 3 scores, $\mathrm{CHADS}_{2}$ is the simplest, and conversely, $\mathrm{CHA}_{2} \mathrm{DS}_{2}$-VASc is the most detailed. According to the study by Hoshino et al, ${ }^{9}$ there was no difference in risk stratification for a poor prognosis between the simple and detailed strategies. Simpler risk stratification may be better because AF is a common disease, and in many cases is managed by general physicians.

Until 2010, warfarin (vitamin K antagonist) was the only class of oral anticoagulant available in Japan. Although the drug is highly effective in preventing thromboembolism, its use is limited because of its narrow therapeutic index, necessitating frequent monitoring and dose adjustments, and thus resulting in substantial risk and inconvenience. In addition, because the Japanese frequently consume foods such as natto (fermented soybeans) that contain vitamin $\mathrm{K}$, the effect of warfarin may not be as substantial. These limitations have translated into poor patient adherence and an insufficient blood concentration of warfarin to prevent ischemic stroke, particularly in the Japanese. Several new oral anticoagulants (NOACs) dose-dependently inhibit thrombin (eg, dabigatran) or factor Xa (eg, rivaroxaban, apixaban, and edoxaban) and have more advantages than warfarin, such as rapid onset and off set of action, effect on dietary vitamin $\mathrm{K}$ intake, and fewer drug interactions. The predictable anticoagulant effects of the NOACs enable the administration of fixed doses without the need for routine coagulation monitoring, thereby simplifying treatment. Clinical trials in which outcomes with NOACs have been compared with those of warfarin (RE-LY ${ }^{10}$ with dabigatran, ROCKET AF ${ }^{11}$ with rivaroxaban, ARISTOTLE ${ }^{12}$ with apixaban, and ENGAGE AFTIMI $48^{13}$ with edoxaban) have shown that each NOAC is at least as safe and effective as warfarin for preventing stroke and systemic embolism in patients with non-valvular AF. Metaanalyses have demonstrated that these 4 NOACs are effective and safe. ${ }^{14}$

\section{Disclosures}

Dr Ikeda reports remuneration (eg, lecture fees) from Nippon Boehringer Ingelheim, Bayer Schering Pharma, Bristol-Myers Squibb, Pfizer Japan, Mitsubishi-Tanabe Pharma, Daiichi Sankyo, Ono Pharmaceutical, Medtronic Japan, and Fukuda Denshi, and research funds (trust research funds, joint research funds, etc.) from Daiichi Sankyo, Mitsubishi-Tanabe Pharma, Bristol-Myers Squibb, Nippon Boehringer Ingelheim, Bayer Schering Pharma, Medtronic Japan, and Fukuda Denshi.

\section{References}

1. Inoue H, Fujiki A, Origasa H, Ogawa S, Okumura K, Kubota I, et al. Prevalence of atrial fibrillation in the general population of Japan: An analysis based on periodic health examination. Int J Cardiol 2009; 137: $102-107$.

2. Iguchi Y, Kimura K, Aoki J, Kobayashi K, Terasawa Y, Sakai K, et al. Prevalence of atrial fibrillation in community-dwelling Japanese aged 40 years or older in Japan: Analysis of 41,436 non-employee residents in Kurashiki-city. Circ J 2008; 72: 909-913.

3. Anderson JL, Halperin JL, Albert NM, Bozkurt B, Brindis RG, Curtis LH, et al. Management of patients with atrial fibrillation (compilation of 2006 ACCF/AHA/ESC and 2011 ACCF/AHA/HRS recommendations): A report of the American College of Cardiology/ American Heart Association Task Force on practice guidelines. Circulation 2013; 127: 1916-1926.

4. Cairns JA, Connolly S, McMurtry S, Stephenson M, Talajic M; CCS Atrial Fibrillation Guidelines Committee. Canadian Cardiovascular Society atrial fibrillation guidelines 2010: Prevention of stroke and systemic thromboembolism in atrial fibrillation and flutter. Can $J$ Cardiol 2011; 27: 74-90.

5. Inoue H, Atarashi H, Okumura K, Kamakura S, Kumagai K, Koretsune Y, et al. Guidelines for Pharmacotherapy of Atrial Fibrillation (JCS 2013). http://www.j-circ.or.jp/guideline/pdf/JCS2013_inoue_h.pdf (accessed April 24, 2014) (in Japanese).

6. Komatsu T, Sato Y, Ozawa M, Kunugita F, Ueda H, Tachibana H. Relationship between CHADS 2 score and efficacy of antiarrhythmic drug therapy in patients with paroxysmal atrial fibrillation. Circ J 2013; 77: 639-645.

7. Camm AJ, Lip GYH, De Caterina R, Savelieva I, Atar D, Hohnloser SH, et al. 2012 focused update of the ESC Guidelines for the management of atrial fibrillation: An update of the 2010 ESC Guidelines for the management of atrial fibrillation. Developed with the special contribution of the European Heart Rhythm Association. Eur Heart J 2012; 33: 2719-2747.

8. Piccini JP, Stevens SR, Chang Y, Singer DE, Lokhnygina Y, Go AS, et al. Renal dysfunction as a predictor of stroke and systemic embolism in patients with nonvalvular atrial fibrillation: Validation of the R2CHADS2 index in the ROCKET AF (Rivaroxaban Once-daily, oral, direct factor Xa inhibition Compared with vitamin K antagonism for prevention of stroke and Embolism Trial in Atrial Fibrillation) and ATRIA (AnTicoagulation and Risk factors In Atrial fibrillation) study cohorts. Circulation 2013; 127: 224-232.

9. Hoshino T, Ishizuka K, Shimizu S, Uchiyama S. CHADS $2, \mathrm{CHA}_{2} \mathrm{DS}_{2-}$ VASc, and $\mathrm{R}_{2} \mathrm{CHADS}_{2}$ scores are associated with the 3-month functional outcome of stroke in patients with prior coronary artery disease. Circ J 2014; 78: $1481-1485$.

10. Connolly SJ, Ezekowitz MD, Yusuf S, Eikelboom J, Oldgren J, Parekh A, et al. Dabigatran versus warfarin in patients with atrial fibrillation. N Engl J Med 2009; 361: 1139-1151.

11. Patel MR, Mahaffey KW, Garg J, Pan G, Singer DE, Hacke W, et al. Rivaroxaban versus warfarin in nonvalvular atrial fibrillation. $N$ Engl J Med 2011; 365: 883-891.

12. Granger CB, Alexander JH, McMurray JJ, Lopes RD, Hylek EM, Hanna M, et al. Apixaban versus warfarin in patients with atrial fibrillation. N Engl J Med 2011; 365: 981-992.

13. Giugliano RP, Ruff CT, Braunwald E, Murphy SA, Wiviott SD, Halperin JL, et al. Edoxaban versus warfarin in patients with atrial fibrillation. N Engl J Med 2013; 369: 2093-2104.

14. Ruff CT, Giugliano RP, Braunwald E, Hoffman EB, Deenadayalu $\mathrm{N}$, Ezekowitz MD, et al. Comparison of the efficacy and safety of new oral anticoagulants with warfarin in patients with atrial fibrillation: A meta-analysis of randomized trials. Lancet 2014; 383: $955-$ 962. 